\title{
Sex determination in gibbons of genus Nomascus using non-invasive method
}

\author{
Petra Bolechová1 ${ }^{1,3}$, Kateřina Ječmínková ${ }^{1,2}$, Michal Hradec ${ }^{1}$, \\ Tomáš Kott ${ }^{2}$, Jana Doležalová ${ }^{4}$ \\ ${ }^{1}$ Czech University of Life Sciences Prague, Department of Animal Science and Ethology, \\ Prague, Czech Republic \\ ${ }^{2}$ Institute of Animal Science, Department of Molecular Genetics, Prague, Czech Republic \\ ${ }^{3}$ Zoo Liberec, Czech Republic \\ ${ }^{4}$ University of Veterinary and Pharmaceutical Sciences Brno, Faculty of Veterinary Medicine, \\ Department of Physiology, Brno, Czech Republic
}

Received June 28, 2016

Accepted October 12, 2016

\begin{abstract}
Gibbons of the genus Nomascus have a strong sexual dimorphism and dichromatism. As they mature, both sexes develop sex-specific pelage colour. In combination with physical similarities in the genitalia with both sexes, there are problems with determining the sex of young individuals compared to other genus of gibbons. This is a pilot study applying a multiplex polymerase chain reactions based on a non-invasive method for sex determination of gibbons. The study was conducted on 22 faecal samples from gibbons of the genus Nomascus. The animals were monitored by staff so that the samples were identified correctly and each sample was collected immediately after the defecation. Results confirmed the sex in all adult and juvenile animals with known sex; and 2 females and 5 males in juveniles were determined with unknown sex. The results of direct examination completely corresponded with the PCR results. The PCR reaction with template DNA isolated from faecal material required BSA usage, however, we observed the occurrence of nonspecific fragments. This did not affect the reliability of our results and we confirmed the usability of this method for this genus.
\end{abstract}

Crested gibbons, sex-typing, multiplex PCR, faeces

Gibbons of the genus Nomascus have a pronounced sexual dimorphism and dichromatism which is detectable only after the onset of physical maturity. Males maintain a black coat with white hair on the cheeks after reaching their physical maturity. In contrast, females change into cream to golden coloured coat with black faces and dark or black hair on the head (Mootnick and Fan 2011). Infants are born buff, by six month of age they begin their colour change, reaching a complete colour change by eighteen months of age. Adult males and immature animals of both sexes are thus blackish in colour (Mootnick 2006).

Identical colouration of young animals makes the sex determination complicated. The situation is further complicated by the fact that female Nomascus are characterized as having a peniform clitoris, and a membrane has been shown to occlude the vulva (Dahl 2015). The clitoris of females is almost as big as the penis and also contains the baculum in contrast to the genus Symphalangus or Hylobates (Hill and Kanagasuntheran 1959; Geismann and Lim 1994; Mootnick 2006). Resemblance to the male is enhanced by black pelage in immature females, causing confusion in identifying their sex (Mootnick 2006; Dahl 2015).

Direct/manual examination of the external genitalia may be used for sexing juveniles, however, it may be stressful for the animal (Deputte and Leclerc-Cassan 1981). Direct examination is not applicable for a daily routine in zoological gardens. To maintain animal welfare and improve animal management abilities in breeding populations of this genus, it is preferable to use a non-invasive method.

Address for correspondence:

Petra Bolechová

Department of Animal Science and Ethology

Czech University of Life Sciences Prague

Kamýcká 129, 165 21, Prague Suchdol, Czech Republic 
One of the other possible methods seems to be observing differences in urination. The male projects a narrow jet from the tip of the penis whereas in the female, urine flows out in a sheet over a breadth corresponding to the length of the labia major (Deputte and Leclerc-Cassan 1981). Although this method can be applied by experienced keepers, mistakes cannot be fully excluded.

Numerous studies describe procedures for sex-determination using the molecular approach (Bradley et al. 2001; Di Fiore 2005; Cadamuro et al. 2015) but for practical use it is more convenient to use one set of primers to determine sex broadly across the primates, to reach a simple and effective assay for a reasonable price.

Studies of Nomascus sex determination are available (Villesen and Fredsted 2006) but the DNA sources were blood samples. Therefore, we decided to follow the methodology according to Di Fiore (2005) to explore it further with regard to gibbons of the genus Nomascus. This method can ensure a high welfare standard and create a useful tool for improving the captive management of the gibbons.

\section{Materials and Methods}

We validated the method on samples from seven zoological parks within the European Association of Zoos and Aquaria, namely on house gibbons of the genus Nomascus (N. leucogenys, N. gabriellae, and N. siki).

For sex typing, analyses of faecal samples from 16 individuals were used. These animals were divided into categories based on age: juveniles: age 0-4 years and adults - over 6 years with full colour change (see Table 1).

Table 1. Data on the sampled gibbons of the genus Nomascus.

\begin{tabular}{|c|c|c|c|c|c|c|c|}
\hline \multirow{2}{*}{$\begin{array}{l}\text { Sample } \\
\text { ID }\end{array}$} & \multirow[b]{2}{*}{ Species } & \multirow[b]{2}{*}{ Zoo/country } & \multirow[b]{2}{*}{ Age category" } & \multirow{2}{*}{$\begin{array}{l}\text { Number } \\
\text { of samples }\end{array}$} & \multicolumn{3}{|c|}{ Sex determination reported by } \\
\hline & & & & & $\begin{array}{c}\text { ZOO before } \\
\text { study }\end{array}$ & Multiplex PCR & $\begin{array}{c}\text { ZOO after } \\
\text { termination of study }\end{array}$ \\
\hline 1 & N. gabriellae & Bojnice/SK & Adult & 3 & Male & Male & Male \\
\hline 2 & N. gabriellae & Bojnice/SK & Adult & 1 & Female & Female & Female \\
\hline 3 & N. gabriellae & Jihlava /CZ & Adult & 1 & Male & Male & Male \\
\hline 4 & N. leucogenys & Liberec/CZ & Juvenile & 1 & Unknown & Male & Male \\
\hline 5 & N. leucogenys & Liberec/CZ & Adult & 1 & Female & Female & Female \\
\hline 6 & N. leucogenys & Liberec/CZ & Juvenile & 1 & Male & Male & Male \\
\hline 7 & $N$. leucogenys & Mulhouse/FR & Juvenile & 1 & Unknown & Female & Female \\
\hline 8 & N. gabriellae & Mulhouse/FR & Juvenile & 2 & Unknown & Male & Male \\
\hline 9 & N. siki & Mulhouse/FR & Juvenile & 2 & Unknown & Male & Male \\
\hline 10 & N. gabriellae & Olomouc/CZ & Juvenile & 1 & Male & Male & Male \\
\hline 11 & N. gabriellae & Olomouc/CZ & Juvenile & 1 & Unknown & Female & Female \\
\hline 12 & N. gabriellae & Olomouc/CZ & Adult & 1 & Female & Female & Female \\
\hline 13 & N. gabriellae & Olomouc/CZ & Juvenile & 1 & Unknown & Male & Male \\
\hline 14 & N. leucogenys & Ostrava/CZ & Juvenile & 3 & Unknown & Male & Male \\
\hline 15 & N. gabriellae & Warszawa/PL & Juvenile & 1 & Male & Male & Male \\
\hline 16 & N. gabriellae & Warszawa/PL & Adult & 1 & Male & Male & Male \\
\hline
\end{tabular}

*Juvenile: age from 0-4 years; Adult: over 6 years

We tested 6 adults with known sex (one male and one female were used as positive controls), 3 juvenile animals with known sex and 7 juveniles with unknown sex. In total, we obtained 22 samples due to multiple sampling of 4 individuals (see Table 1). Multiple sampling was used for verification of the method tested.

The animals were monitored by staff in order for the samples to be taken and identified correctly. The samples were collected from each individual immediately after defecation and then all samples were frozen at $-20{ }^{\circ} \mathrm{C}$ 
until DNA extraction. For molecular analysis we extracted DNA from faeces using the QIAamp DNA Stool Mini Kit (Qiagen, Germany). To determine the sex we used Multiplex PCR with 2 pairs of primers amplifying the fragments of the Amelogenin X gene (AMEL) and/or of Y-linked sex-determining region gene (SRY) previously described by Di Fiore (2005).

The regular volume of each PCR reaction was $10 \mu$, which included 20-50 ng genomic DNA, $1 \times$ PPP Master with $\mathrm{MgCl}_{2}(5 \mathrm{mM})$ (Top-Bio, Czech Republic), $0.4 \mu \mathrm{M}$ of each primer (Generi Biotech, Czech Republic) and $0.1 \mu \mathrm{g} / \mu \mathrm{l} \mathrm{BSA}$ (Sigma-Aldrich, USA). Thermal cycling conditions were as follows: $2 \mathrm{~min}$ at $94{ }^{\circ} \mathrm{C}, 43 \mathrm{cycles}$ of $94^{\circ} \mathrm{C}$ for $30 \mathrm{~s}, 56.8^{\circ} \mathrm{C}$ annealing temperature for $30 \mathrm{~s}$, and $72{ }^{\circ} \mathrm{C}$ for $30 \mathrm{~s}$, followed by a final extension of $72{ }^{\circ} \mathrm{C}$ for $5 \mathrm{~min}$. Afterwards we subjected amplified fragments by electrophoretic separation on 3\% GelRed-stained (Biotium, USA) agarose gel (Lonza, Switzerland).

\section{Results}

The electrophoretic separation showed 194 bp fragments of the AMEL and/or $164 \mathrm{bp}$ of SRY. We distinguished the sex of the individual based on the presence or absence of the SRY band (Fig. 1). The procedure was repeated three times for each sample and the No. Template Control was used to negate contamination. By this method the sex was confirmed for all adults and juveniles as determined before. For animals with unknown sex we determined 2 females and 5 males in juveniles. After determination by multiplex PCR, their sex was also later confirmed by their zoo keepers. The results of direct examination completely corresponded with the PCR results and therefore we can state that the method is highly reliable (see Table 1).

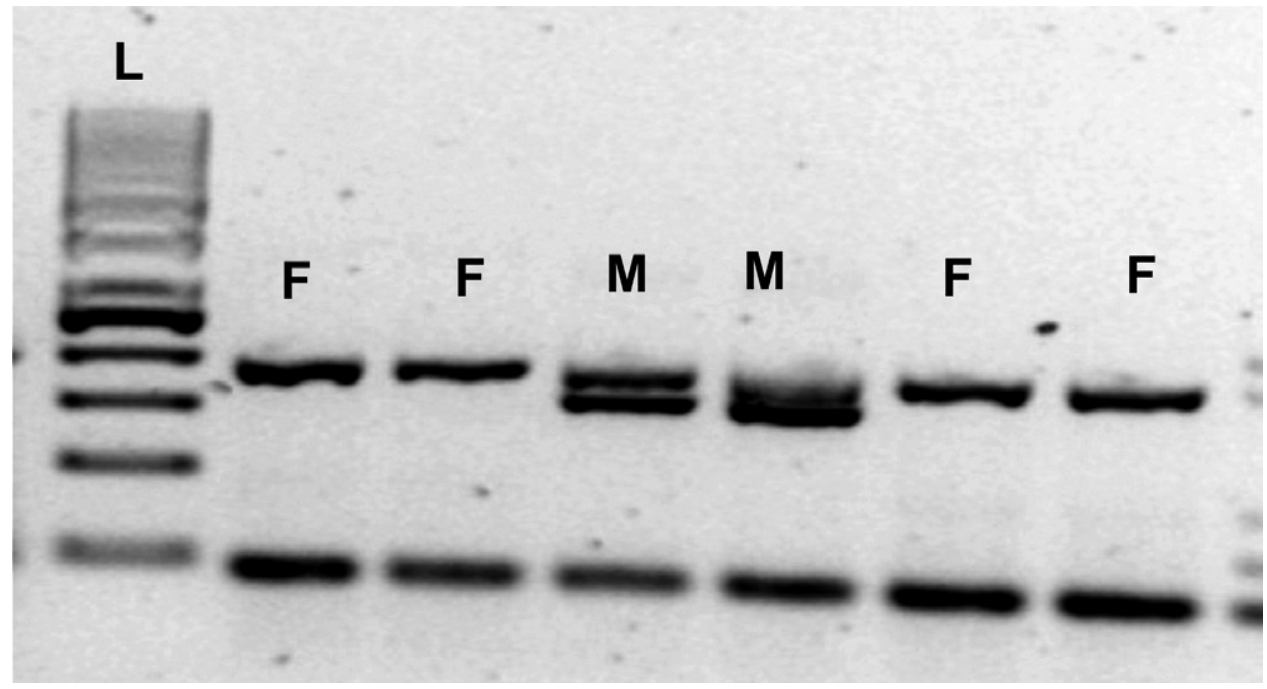

Fig. 1. An example of sex determination ( $\mathrm{M}$ - male, $\mathrm{F}-$ female, $\mathrm{L} 50$ bp ladder)

\section{Discussion}

In our study, we presented the first demonstration of sex determination by the noninvasive PCR method for Nomascus gibbons.

As mentioned, a number of factors make the sex determination of the offspring in Nomascus gibbons difficult, particularly, the same colour of the coat in immature males and females with coat father and their overlapping adult weight ranges (Mootnick 2006; Mootnick and Fan 2011). Unfortunately, most zoos use experienced staff for sex determination or it is done during routine veterinary examinations. Such determination 
is not always reliable, and errors can occur, which makes the breeding of these gibbons complicated.

Few studies describe processes for sex-typing in monkeys, apes and also gibbons by amplification of the SRY or/and AMEL gene (Di Fiore 2005; Cadamuro et al. 2015). In our study, the amplification of SRY ran with great efficiency but in some cases we observed preferential amplification of the $\mathrm{Y}$ fragment. Nonetheless, the $\mathrm{X}$ fragment was still clearly visible on the gel. Similar situation was reported in Strepsirrhini (Di Fiore 2005) and also in New World Monkeys (Platyrrhini) (Villesen and Fredsted 2015). We assume that this lower AMEL amplification efficiency could be a problem of sample quality rather than a problem of the taxa. The DNA sample isolated from faeces does not contain just the target DNA of the animal but also the DNA of intestinal bacteria and food. The PCR reaction with template DNA isolated from such a medley material as faeces required the use of BSA, however, we observed the occurrence of nonspecific fragments. This did not affect the reliability of our results. In conclusion, there is potential for using multiple PCR in routine practice for animal species where sex determination in juveniles is not obvious.

\section{Acknowledgements}

We would like to thank all the curators and keepers of primates of the Liberec, Olomouc, Ostrava, Jihlava, Bojnice, Mulhouse, and Warsaw zoos. The study was supported by grant No. MZERO0714 from the Czech Ministry of Agriculture and by IGA VFU Brno 33/2011/FVL.

\section{References}

Bradley BJ, Chambers KE, Vigilant L 2001: Accurate DNA-based sex identification of apes using non-invasive samples. Conserv Genet 2: 179-181

Cadamuro VC, Bouakaze C, Croze M, Schiavinato S, Tonasso L, Gerard P, Fausser JL, Gibert M, Dugoujon JM, Braga J, Balaresque P 2015: Determined about sex: Sex-testing in 45 primate species using a 2Y/1X sex-typing assay. Forensic Sci Int Genet 14: 96-107

Dahl JF 2015: A Comparative Study of the external genitalia of female Hylobatids: Adolescent Nomascus masquerade as males. Am J Phys Anthropol 156: 115-115

Deputte BL, Leclerc-Cassan M 1981: Sex determination and age estimation in the White-cheeked gibbon. Hylobates concolor leucogenys anatomical and behavioral features. Int ZOO Yearb, Volume 21: 187-193

Di Fiore A 2005: A rapid genetic method for sex assignment in non-human primates. Conserv Genet 6: 1053-1058

Geissmann T, Lim KKP 1994: Extraction of bacula from tanned gibbon skins. Raff Bull Zool 42: 775-780

Hill WCO, Kanagasuntheram R 1959: The male reproductive organs in certain gibbons (Hylobatidae). Am J Phys Anthropol 17: 227-241

Mootnick AR 2006: Gibbon (Hylobatidae) species identification recommended for rescue or breeding centres. Primate Conserv 21: $103-138$

Mootnick AR, Fan PF 2011: A comparative study of crested gibbons (Nomascus). Am J Primatol 73: 135-154

Villesen P, Fredsted T 2006: A new sex identification tool: One primer pair can reliably sex ape and monkey DNA samples. Conserv Genet 7: 455-459 